CORRECTION

https://doi.org/10.1038/s41586-018-0351-4

\title{
Author Correction: Gamma frequency entrainment attenuates amyloid load and modifies microglia
}

Hannah F. Iaccarino, Annabelle C. Singer, Anthony J. Martorell, Andrii Rudenko, Fan Gao, Tyler Z. Gillingham, Hansruedi Mathys, Jinsoo Seo, Oleg Kritskiy, Fatema Abdurrob, Chinnakkaruppan Adaikkan, Rebecca G. Canter, Richard Rueda,

Emery N. Brown, Edward S. Boyden \& Li-Huei Tsai

Correction to: Nature https://doi.org/10.1038/nature20587, published online 07 December 2016.

In Extended Data Fig. 8 of this Article, we inadvertently copied the data between $A \beta_{1-40}$ levels at $1 \mathrm{~h}$ and $A \beta_{1-42}$ levels at $1 \mathrm{~h}$. We have corrected the $A \beta_{1-42}$ graph and re-run the statistical analysis. We see a significant reduction in $A \beta_{1-40}$ and $A \beta_{1-42}$ levels $1 \mathrm{~h}$ after $40 \mathrm{~Hz}$ flicker, consistent with the other independent replications in the Article and with our immunohistochemistry analysis of $\mathrm{A} \beta$ plaques. Our overall findings and conclusions are not changed by these results. We also accidentally omitted the raw ELISA data values for $A \beta_{1-40}$ and $A \beta_{1-42}$, for 'Dark 1hr' and ' $40 \mathrm{~Hz} 1 \mathrm{hr}$ wait $1 \mathrm{hr}$ ' in Extended Data Table 1. The Supplementary Information to this Amendment contains the old, incorrect Extended Data Fig. 8 and Extended Data Table 1, for transparency. These errors have been corrected online.

Supplementary information is available for this Amendment at https://doi. org/10.1038/s41586-018-0351-4. 